\title{
Philanthropy, diplomacy and built environment expertise at the Calouste Gulbenkian Foundation in the 1960s and 1970s
}

\author{
Ricardo Costa Agarez \\ Department of Architecture \\ University of Évora, Portugal \\ ragarez@uevora.pt
}

When the Calouste Gulbenkian Foundation was established in Portugal in 1956, its endowments were channelled to support priority charitable, educational, scientific and arts-related initiatives, both in the country and abroad. To this end, the trust erected a political, diplomatic, technical and administrative machine that, in the second half of the twentieth century, was uncommon there; its Projects and Works Department, SPO (19571992), became a built environment production bureaucracy staffed by architects and civil engineers with solid design and technology cultures, working in a finely tuned, relatively well-resourced apparatus. This paper investigates the role of the Gulbenkian Foundation and the SPO in nurturing architectural and engineering research and furthering building science expertise by analysing the aims, structure, work processes, knowledge references, opportunities and reversals of this bureaucracy. I suggest that the SPO, given a mandate for professional excellence, played an essential part in the establishment and consolidation of the Foundation, in Portugal and internationally, with what aimed to be a prompt, efficient, architecturally and technically sophisticated brick-and-mortar presence that would simultaneously help assert and preserve its independence, both ideological and material. The latter was certainly paramount, and the SPO's architecturaltechnical expertise was put to full use within the Foundation's soft-power diplomacy strategy in Iraq, where this department's action was instrumental in maintaining access to the philanthropy's oil-concession resources.

\section{Introduction}

As we have seen in other proposals submitted to the Foundation in recent years for projects in Iraq, there is a significant drive for renewal in architecture, particularly in its effort to adjust the demands, means available and needs of modern life to a 'style' that aims to be rooted in tradition. ... Good architecture in Iraq is no longer a more or less successful adaptation of the rectilinear, functional modern architecture that spread across the world. Glass curtain-walls, exposed interiors, emphatic modulation - these are no longer the signs of avant-garde architecture in Iraq as buildings increasingly feature almost hermetic façades, concise openings that follow traditional models, layouts punctuated with patios, etc. This, without compromising the materials and structures employed ... not concealed but easily made evident in the work of talented designers. ${ }^{1}$ 